\title{
O CÍRCULO VICIOSO DA POBREZA: ANÁLISE DA ESTRATÉGIA DO PROGRAMA BOLSA FAMÍLIA NOS MUNICÍPIOS DO COREDE DO VALE DO RIO PARDO
}

\author{
Bruna Taize de Medeiros" \\ Cidonea Machado Deponti* \\ Rosane Bernardete Brochier Kist"
}

\begin{abstract}
Resumo
O Brasil, apesar de ser uma das maiores economias do mundo, apresenta ainda grandes desigualdades socioeconômicas. Como estratégia de combate à fome e à pobreza foi criado, em 2003, o Programa Bolsa Família, que em 12 anos conseguiu retirar mais de 36 milhões de pessoas da situação de miséria e pobreza. O objetivo principal deste artigo é analisar se o Bolsa Família contribuiu para reduzir o círculo vicioso da pobreza destacado pelo economista Gunnar Myrdal (1997) em sua abordagem teórica sobre o desenvolvimento. No que se refere às questões metodológicas deste artigo, realizou-se uma pesquisa documental acerca da teoria de desenvolvimento de Myrdal (1997), juntamente com uma análise descritiva baseada em dados secundários do Programa Bolsa Família em nível regional no Conselho Regional de Desenvolvimento (COREDE) do Vale do Rio Pardo. Constatou-se que o Bolsa Família pode contribuir para corromper o círculo vicioso da pobreza que Myrdal (1997) retrata em sua teoria, pois contribui para à redução da fome e da desnutrição, visto que grande parte dos benefícios é utilizada para o atendimento das necessidade básicas das famílias, especialmente da alimentação. Evidenciou-se, ainda, que os dados analisados indicam que há uma possibilidade de o Bolsa Família contribuir para o processo de erradicação da extrema pobreza no país e na quebra do seu
\end{abstract}

\footnotetext{
* Mestra em Desenvolvimento Regional da Universidade de Santa Cruz do Sul (PPGDR/UNISC). Professora do Curso de Ciências Econômicas da Universidade Federal do Pampa (UNIPAMPA).

E-mail: bt_medeiros@hotmail.com.

** Professora do Programa de Pós-Graduação em Desenvolvimento Regional da Universidade de Santa Cruz do Sul (PPGDR/UNISC). E-mail: cidonea@unisc.br

*** Pós-Doutoranda Bolsista DOCFIX - Coordenação de Aperfeiçoamento de Pessoal de Nível Superior (CAPES) e Fundação de Amparo à Pesquisa do Estado do Rio Grande do Sul (FAPERGS). Professora do Programa de Pós-Graduação em Desenvolvimento Regional da Universidade de Santa Cruz do Sul (PPGDR/ UNISC).E-mail: rosanekist@unisc.br.
} 
48 ReVISTA Grifos

círculo vicioso, caso os resultados do Programa apresentem o mesmo desempenho identificado na última década. Por fim, embora se reconheçam os inúmeros benefícios deste programa, há que se considerar, ainda, a necessidade de articulação do Programa Bolsa Família com outras políticas públicas.

Palavras-chave: Círculo Vicioso. Pobreza. Programa Bolsa Família.

\section{Introdução}

A pobreza é vivenciada por milhares de pessoas no mundo inteiro. Combater esta realidade significa enfrentar um passado de injustiça social, visto que grande parte da população, especialmente a brasileira, tem sido excluída do acesso aos serviços sociais básicos e aos direitos de cidadania. Definir o conceito de pobreza nem sempre é uma tarefa fácil, sendo possível estudá-la a partir de perspectivas que privilegiam a renda mínima de sobrevivência ou com base em perspectivas mais abrangentes, considerando questões mais amplas, como o atendimento de serviços sociais básicos, especialmente nas áreas da saúde, da educação e da assistência social. No Brasil, especialmente a partir da promulgação da Constituição Federal de 1988, a temática da pobreza passou a receber maior destaque na agenda pública. Criaram-se, a partir da década de 1990, vários programas nacionais que, posteriormente, foram unificados no Programa Bolsa Família, com o objetivo de combater níveis de pobreza.

A execução de programas sociais busca propiciar a criação de uma rede de proteção social e a manutenção dos padrões de vida dos cidadãos, programas estes que são motivados “[...] pela existência de falhas de mercado, assimetria de informações, externalidades positivas e negativas e mercado de crédito imperfeito" (CAMARGO, 2004, p. 68).

$\mathrm{O}$ objetivo principal deste artigo é verificar se o Bolsa Família contribuiu para reduzir o círculo vicioso da pobreza destacado pelo economista Gunnar Myrdal (1997) em sua abordagem teórica sobre o desenvolvimento. No que se refere às questões metodológicas deste artigo, realizou-se uma 
pesquisa documental acerca da teoria de desenvolvimento de Myrdal (1997), juntamente com uma análise descritiva baseada em dados secundários do Programa Bolsa Família em nível nacional, publicada pelo Ministério do Desenvolvimento Social e Combate à Pobreza (MDS) em 2015.

Este artigo está dividido em três seções além da introdução. A primeira seção apresenta alguns elementos da Teoria do Desenvolvimento de Gunnar Myrdal; a segunda, aborda o Programa Bolsa Família; na terceira, apresentam-se alguns dados sobre os efeitos do Bolsa Família no processo de redução do círculo vicioso da pobreza no Brasil. Ao final, apresentam-se algumas conclusões sobre o tema.

\section{A abordagem teórica de Myrdal}

Gunnar Myrdal (1898-1987), economista e político sueco, ganhador do Prêmio Nobel em 1974 juntamente com Friedrich August Von Hayek, é considerado um dos maiores especialistas sobre o tema da pobreza e do subdesenvolvimento. Em 1956 escreveu sua obra "Teoria Econômica das Regiões Subdesenvolvidas", na qual comparou o desenvolvimento econômico entre países desenvolvidos e em desenvolvimento. Ao longo de sua abordagem teórica, Myrdal se aproxima da visão keynesiana quando se refere à necessidade de intervenção do Estado no aumento dos investimentos.

Para exposição de sua compreensão Myrdal se utiliza do conceito denominado Princípio de Causação Circular Cumulativa, por meio da qual o autor analisa as relações estabelecidas entre espaços desequilibradamente desenvolvidos, que acarretariam crescentes agravamentos das disparidades em níveis de desenvolvimento dos países. De forma geral, este princípio busca explicar porque determinadas regiões são desenvolvidas e outras não. Também seria possível compreender porque uma determinada região é subdesenvolvida e quais as medidas a serem tomadas para superar o subdesenvolvimento. De acordo com Myrdal, quanto maior a compreensão de como os fatores se inter-relacionam, 
tanto maior a capacidade de alcançar bons resultados em termos de política. $\mathrm{O}$ processo de causação circular cumulativa considera o sistema econômico instável e desequilibrado.

De acordo com Lima e Simões (2009), Myrdal recorre à noção de círculo vicioso para explicar como o processo se torna circular e cumulativo, no qual um fator negativo é ao mesmo tempo causa e efeito de outros fatores negativos. Quanto maior o nível de desenvolvimento de um país, maior os spread effects (efeitos propulsores) e mais fácil a neutralização dos backwash effects (efeitos de polarização).

Para Myrdal, a noção de equilíbrio estável traria implícita e ideia de que, em resposta a uma mudança em determinada direção, surgiriam, automaticamente mudanças secundárias em direção oposta à primeira, de modo a neutralizá-la. Assim, não seria verificável uma tendência automática à estabilização do sistema social; pelo contrário, haveria sim uma tendência de afastamento do estado dito de equilíbrio, algo que seria explicável pelo processo de causação circular cumulativa. Portanto, se este processo cumulativo, alimentado pela causação circular, não fosse controlado, promoveria desigualdades crescentes. Neste sentido, Myrdal afirma que o problema dos países subdesenvolvidos reside em efeitos propulsores fracos que, deixados nas livres forças do mercado, provocam a geração ou a ampliação das desigualdades regionais nestes países, e as próprias desigualdades representam obstáculos ao progresso (CARDOSO, 2012).

Resumidamente este princípio afirma que uma determinada região, a partir de um efeito propulsor, pode se tornar desenvolvida e esse efeito positivo pode promover um aumento de investimentos para a localidade tornando-a um polo de desenvolvimento. Por outro lado, este efeito pode ocorrer de forma negativa gerando regressão, acentuando ainda mais o caráter de subdesenvolvimento de determinadas regiões. Isso ocorre porque regiões prósperas tendem a atrair cada vez mais desenvolvimento originado de investimentos oriundos de regiões mais pobres. 
Myrdal (1997) explica que esse processo de causação circular cumulativa da pobreza amplia as desigualdades entre países prósperos e países pobres, e, consequentemente, ocasiona disparidade entre seus respectivos níveis de desenvolvimento. Segundo Myrdal (1997, p. 34): “[...] Assim, um homem pobre talvez não tenha o bastante para comer; sendo subnutrido, sua saúde será fraca; sendo fraco, sua capacidade de trabalho será baixa, o que significa dizer que será pobre, $o[\ldots]$ que implica dizer que não terá o suficiente para comer; e assim por diante [...]".

Segundo a Teoria de Myrdal, esse modelo somente seria interrompido pela aplicação planejada de reformas e de políticas econômicas, através da ação do Estado, ou seja, sugere intervenções políticas planejadas para que se consiga um equilíbrio estável e a redução dos níveis de pobreza. Defende que o Estado deve agir como um agente de promoção do desenvolvimento regional; pois, se o país é deixado às forças do mercado, o que se verifica é uma geração ou ampliação das desigualdades regionais. A relação entre os efeitos propulsores fracos e as desigualdades representam as interdependências que retroalimentam o processo cumulativo - "a pobreza se torna sua própria causa” (MYRDAL, 1997, p. 63). De acordo com Cardoso (2012), a análise do autor aproxima-se daquela defendida por Nurske (1957 [1953], p. 8), e, quando este afirma que um "país é pobre porque é pobre", guarda paralelos com os encadeamentos para frente e para trás de Hirschman (1958) e com os efeitos propulsores das economias externas de Rosenstein-Rodan $(1943,1944)$.

Para Myrdal (1997), a miséria leva as pessoas a serem mais propícias a terem doenças, o que, por sua vez, implica a queda de produtividade do trabalho e o agravamento do quadro de pobreza. Assim, é necessária a realização de intervenções estatais que contribuam para elevar o patamar de desenvolvimento econômico a fim de reduzir os indicadores de mortalidade. A redução da pobreza poderia propiciar ao indivíduo um poder de compra maior e ampliaria sua capacidade e a produtividade do trabalho, o que resultaria em 
salários maiores, constituindo-se em um processo cumulativo em ascensão. Dessa forma, segundo Myrdal, o círculo vicioso do atraso econômico e da pobreza poderia ser interrompido por meio das intervenções do Estado com vistas à promoção do crescimento econômico com integração nacional.

No Brasil, a adoção de políticas planejadas para o controle da pobreza se intensificou a partir de 1995, com a criação do Programa de Erradicação do Trabalho Infantil (PETI), durante os anos 2000, em que foram criados os Programas Bolsa Escola, Bolsa Alimentação, Cartão Alimentação e Vale Gás. Posteriormente, em 2003, esses programas foram unificados no Programa Bolsa Família, que é considerado pela ONU o maior programa de transferência de renda já realizado no mundo e a maior estratégia de combate à fome.

Tal unificação fez-se necessária em virtude da sobreposição de programas existentes, de objetivos e de público-alvo, além da falta de coordenação e de dispersão de programas em diversos Ministérios. Sanson (2007) afirma em seu trabalho que a unificação dos programas permitiu maior agilidade na liberação dos benefícios, reduziu a burocracia e tornou mais transparente o controle dos recursos, originando, assim, o Programa que é considerado como o "carro-chefe" da política social no Brasil.

$\mathrm{Na}$ próxima seção serão apresentados os objetivos, as normativas, as características, os tipos de benefícios do Programa Bolsa Família.

\section{O Programa Bolsa Família}

No ano de 2003 houve a unificação dos Programas já referidos, através da criação do Programa Bolsa Família (PBF), instituído pela Medida Provisória no 132, de 20 de outubro de 2003, transformada na Lei no 10.836 , de 9 de janeiro de 2004, regulamentada pelo Decreto no 5.209 , de 17 de setembro de 2004 (SILVA, 2005). Este processo se fez necessário devido a questões como a sobreposição dos objetivos e do públicoalvo, a falta de planejamento do orçamento, além da falta de 
alcance ao público-alvo conforme os critérios de elegibilidade do programa, entre outros aspectos (SILVA, 2007).

Segundo o MDS (2015), o Bolsa Família possui três eixos principais: a transferência de renda, visando à promoção do alívio imediato da pobreza; as condicionalidades, que reforçam o acesso a direitos sociais básicos nas áreas de educação, de saúde e de assistência social; e as ações e os programas complementares, que visam ao desenvolvimento das famílias na perspectiva da superação da situação de vulnerabilidade.

Conforme MDS (2015, p. 1), os benefícios concedidos pelo Programa são divididos em:

Benefício Básico: Cedido às famílias com renda igual ou menor de $\mathrm{R} \$ 77,00$ reais mensais, limitado a cinco membros por família; Benefício Variável: Cedido às famílias que tenham crianças e/ou adolescentes de 0 a 15 anos, no valor de $\mathrm{R} \$ 35,00$ reais mensais, limitado a cinco membros por família; Benefício Variável à Gestante (BVG): Cedido às famílias que tenham gestantes, o valor repassado é de $R \$ 35,00$ mensais durante nove meses interruptos, limitado a cinco membros por família. A identificação da gravidez é realizada no Sistema Bolsa Família na Saúde. O Cadastro Único não permite identificar as gestantes. Benefício Variável à Nutriz (BVN): Cedido as famílias que tenham crianças entre 0 e 6 meses, o valor repassado é de $\mathrm{R} \$ 35,00$ reais mensais durante seis meses ininterruptos, limitados a cinco membros por família. Benefício Variável Vinculado ao Adolescente (BVJ): Cedido às famílias que tenham adolescentes com idade entre 16 e 17 anos, no valor de $R \$ 42,00$ mensais, limitado a dois adolescentes por família. Benefício para Superação da Extrema Pobreza (BSP): Benefício calculado caso a caso dependendo da situação da família.

Os responsáveis pelo acompanhamento das contrapartidas são os agentes municipais, além de responderem, também, pela oferta de grande parte dos serviços de educação e de saúde necessários para que as famílias possam cumprir suas contrapartidas. Identifica-se, assim, o papel estratégico 
1 A partir desta área, as crianças e adolescentes com até 15 anos em risco ou retiradas do trabalho infantil pelo Programa de Erradicação do Trabalho Infantil (PETI), devem participar dos Serviços de Convivência e Fortalecimento de Vínculos (SCFV) do Peti e obter frequência mínima de $85 \%$ da carga horária mensal.

2 A cobrança das contrapartidas educacionais é realizada pelas secretarias municipais de educação e consolidada pelo MEC. Através do Cadastro Único o MEC gera uma lista de crianças (indexada pelo Número de Informação Social (NIS) e o código da escola constante do último registro do cadastro), e repassa para o MEC, que a distribui para as secretarias municipais de educação. As escolas cujos diretores têm acesso à internet recebem da secretaria uma senha para preencher a frequências das crianças cujas famílias recebem benefícios diretamente. O acompanhamento das contrapartidas de saúde é coordenado pelo Ministério de Saúde e realizado pelas secretarias municipais de saúde (SOARES; SÁTYRO, 2010). que os municípios possuem no processo de funcionamento do PBF; pois, se não houver um empenho destes e uma gestão qualificada, pode haver o comprometimento do programa (SOARES; SÁTYRO, 2010).

As condicionalidades do programa se caracterizam como "compromissos" assumidos tanto pelas famílias beneficiárias como pelo poder público, visando à ampliação do acesso desses sujeitos aos seus direitos sociais básicos. Dessa forma, as famílias passam a assumir algumas obrigações para continuarem recebendo o benefício, ao passo que o poder público se responsabiliza pela oferta de serviços públicos especialmente nas áreas da educação, saúde e assistência social ${ }^{1}$.

O processo de gestão destas condicionalidades é realizado pelo Ministério do Desenvolvimento Social e Combate à Fome (MDS) através do acompanhamento de forma articulada com os Ministérios da Educação e da Saúde. Em nível municipal este processo deve ocorrer de forma intersetorial, abrangendo as áreas da saúde, da educação e da assistência social ${ }^{2}$.

$\mathrm{Na}$ área de saúde, as famílias têm o compromisso de acompanhar o cartão de vacinação e o crescimento e desenvolvimento das crianças até os 7 anos de idade. As mulheres com idade entre 14 e 44 anos também devem fazer o acompanhamento, e gestantes ou nutrizes devem fazer o prénatal e o acompanhamento da sua saúde e do bebê. $\mathrm{Na}$ área da educação, todas as crianças e adolescentes com idade entre 6 e 15 anos devem estar matriculados e com frequência escolar mensal de, no mínimo, 85\%; já os estudantes com idades entre 16 e 17 anos devem ter, no mínimo, 75\% de frequência. $\mathrm{Na}$ área da assistência social as crianças e adolescentes com até 15 anos em risco ou retiradas do trabalho infantil pelo Programa de Erradicação do Trabalho Infantil (PETI), devem participar dos Serviços de Convivência e Fortalecimento de Vínculos (SCFV) do PETI e obter frequência mínima de 85\% da carga horária mensal (BRASIL, 2015).

Soares e Sátyro (2010) referem que existem diferentes posicionamentos quanto à exigência das contrapartidas às 
famílias beneficiárias do PBF. Alguns autores defendem que

o atendimento das contrapartidas é tão importante quanto o recebimento do próprio benefício; afinal, a partir desta visão, o PBF seria como um incentivador do capital humano das famílias mais pobres. Os defensores de uma segunda vertente compreendem que o PBF representa uma proteção social, visto que, dessa forma, se forem exigidas contrapartidas muito rígidas, justamente as famílias beneficiárias, que são as mais vulneráveis, não terão condições de atendê-las. Há, ainda, uma terceira visão a partir da área do Direito que afirma com veemência que se o PBF se transforma em um direito, não pode ser exigida nenhuma contrapartida das famílias beneficiárias. No contexto deste trabalho, compreendemos que o Programa Bolsa Família representa uma proteção social para as famílias que se encontram em situação de vulnerabilidade social; entretanto, para que ele seja efetivo, deve garantir que as pessoas tenham de fato garantidos seus direitos socioassistenciais.

O perfil das famílias usuárias do Programa Bolsa Família nos municípios do COREDE do Vale do Rio Pardo

O Conselho Regional de Desenvolvimento (COREDE) do Vale do Rio Pardo está localizado na região Centro-Oriental do Estado do Rio Grande do Sul/Brasil e é composto por 23 municípios: Arroio do Tigre, Boqueirão do Leão, Candelária, Encruzilhada do Sul, Estrela Velha, General Câmara, Herveiras, Ibarama, Lagoa Bonita do Sul, Mato Leitão, Pantano Grande, Passa Sete, Passo do Sobrado, Rio Pardo, Santa Cruz do Sul, Segredo, Sinimbu, Sobradinho, Tunas, Vale do Sol, Vale Verde, Venâncio Aires e Vera Cruz.

A população total do COREDE do Vale do Rio Pardo é constituída por 418.141 habitantes, sendo que, o total de famílias beneficiárias do PBF no mês de abril de 2015 era de 20.480. Conforme a denominação do Ministério de Desenvolvimento Social e Combate à Fome (BRASIL, 2015), quando se refere à família beneficiária do Programa 
Bolsa Família consideram-se, em média, quatro pessoas como o total de integrantes.

A seleção das famílias usuárias do Programa Bolsa Família ocorre com base nas informações registradas pelos municípios no Cadastro Único para Programas Sociais do Governo Federal (CadÚnico), um instrumento de coleta e de gestão de dados que tem como objetivo identificar todas as famílias de baixa renda existentes no país.

O processo de ingresso das famílias no Programa ocorre a partir de três critérios básicos:

- Famílias com cadastros atualizados nos últimos 24 meses.

- Famílias com renda mensal por pessoa menor ou igual ao limite de extrema pobreza $(\mathrm{R} \$ 77,00)$.

- Famílias com renda mensal por pessoa entre os limites de extrema pobreza e pobreza $(\mathrm{R} \$ 77,01$ e $\mathrm{R} \$ 154,00)$, desde que possuam crianças e/ou adolescentes de 0 a 17 anos na sua composição.

Criado em 2001, com o objetivo de possibilitar a constituição de um Cadastro Único para Programas Sociais, o CadÚnico propicia o cadastramento e a manutenção atualizada de dados das famílias brasileiras que possuem renda per capita inferior a $R \$ 120,00$. Cabe aos municípios a realização do cadastro e a manutenção dos dados atualizados das famílias, a partir das prefeituras. Com base nestes dados o MDS realiza de forma mensal uma seleção automatizada das famílias que serão incluídas no PBF, com base no critério da renda mensal percapita, sendo priorizadas aquelas que possuem renda mensal per capita inferior a $\mathrm{R} \$ 77,00$ (BARROS; CARVALHO; MENDONÇA, 2010). No entanto, o cadastramento não implica a entrada imediata das famílias no programa e no recebimento do benefício.

No caso dos municípios que compõem o COREDE do Vale do Rio Pardo, observa-se que do total de 50.813 famílias inscritas no CadÚnico, consideradas como "famílias potenciais" para o recebimento do benefício, atualmente há 20.480 famílias beneficiárias do Programa Bolsa Família, o 
que representa um percentual de $40,30 \%$ em relação ao total

de inscritos. Estes dados, porém, evidenciam que, em nível regional, há uma maior abrangência de usuários que em nível de estado, visto que, do total de 1.103 .879 famílias gaúchas cadastradas no CadÚnico apenas 414.957 recebem o benefício, o que corresponde a um percentual de 37,59\% em relação ao total de famílias cadastradas. Em nível nacional, estes índices são mais elevados; afinal, há 13.732.792 famílias beneficiárias, o que corresponde a 50,79\% do total de 27.037.471 famílias cadastradas (BRASIL, 2015).

A análise por município evidencia que a maior concentração de famílias beneficiárias do Programa Bolsa Família no COREDE do Vale do Rio Pardo está nos seguintes municípios: Santa Cruz do Sul, que apresenta o maior número de inscritos e beneficiados, contendo 3.514 famílias beneficiárias, o que corresponde a 34,13\% do total de 10.294 famílias inscritas; em segundo lugar, está o município de Venâncio Aires, que possui um total de 2.759 famílias beneficiárias, o que corresponde a 36,19\% do total de 7.629 famílias inscritas; em terceiro lugar, encontra-se o município de Rio Pardo, com um total de 3.110 famílias beneficiárias, o que corresponde a 57,41\% do total de 5.417 famílias inscritas; o município de Encruzilhada do Sul encontra-se em quarto lugar, com um total de 2.002 famílias beneficiárias, o que corresponde a 44,91\% do total de 4.457 famílias inscritas, conforme pode ser evidenciado na Tabela 1 .

No que se refere aos dados percentuais, evidenciase que, com exceção de Santa Cruz do Sul, que apresenta o maior número de famílias inscritas e beneficiárias, o maior percentual de famílias beneficiárias com relação à população total de inscritos no CadÚnico, os municípios de Venâncio Aires, Rio Pardo e Encruzilhada do Sul, embora possuam os maiores números de beneficiários, ocupando da segunda à quarta colocação; não apresentam, na mesma ordem, os maiores percentuais de famílias beneficiárias com relação ao total de famílias inscritas. 
Em termos percentuais, os municípios que apresentam os maiores índices depois de Santa Cruz do Sul são sucessivamente: Herveiras, com um total de 136 famílias beneficiárias, o que corresponde a $48,22 \%$ do total de famílias inscritas; seguido de Tunas, com 424 famílias beneficiárias, o que corresponde a 47,48\% do total de 893 famílias inscritas; e, em quarto lugar, está o município de Sinimbu, que apresenta um total de 467 famílias beneficiárias, o que significa um percentual de 46,51\% em relação ao total de 1.004 famílias inscritas no CadÚnico.

Soares e Sátyro (2010) ressaltam a importância do papel que os profissionais que atuam nos municípios possuem no que se refere à inclusão das pessoas no $\mathrm{PBF}$, pois a seleção das famílias que ingressarão no programa é realizada pelo Ministério de Desenvolvimento Social, a partir dos dados cadastrados no CadÚnico. Este cadastro, por sua vez, é preenchido pelos agentes municipais que decidem quem será ou não "potencial beneficiário" de uma "bolsa família".

No que se refere ao sexo, observa-se que nos municípios do COREDE do Vale do Rio Pardo há uma predominância do sexo feminino - correspondente a $55,31 \%$ do total de beneficiários, conforme pode ser observado na Figura 1.

Figura 1 - Pessoas beneficiárias do PBF por sexo

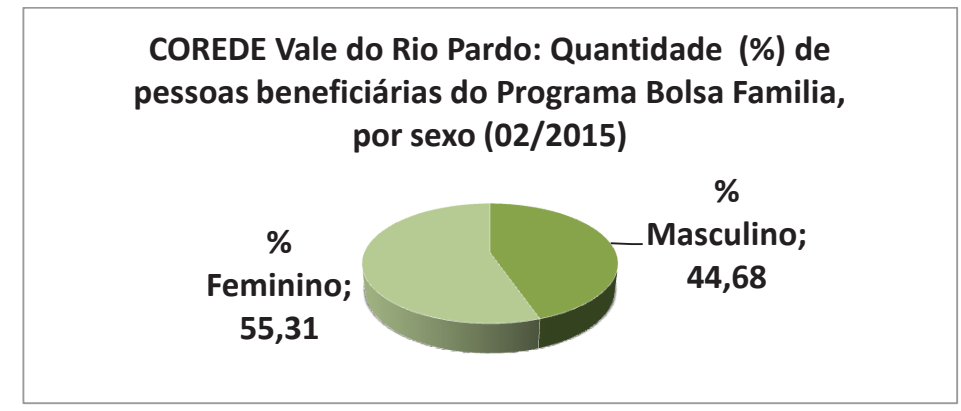

Fonte: Caixa Econômica Federal (2015). 
Tabela 1 - Famílias inscritas no CadÚnico e famílias beneficiárias do Programa Bolsa Família nos municípios do COREDE do Vale do Rio Pardo

\begin{tabular}{|c|c|c|c|}
\hline Municípios & $\begin{array}{c}\text { Total Famílias } \\
\text { Inscritas Cadastro } \\
\text { Único* }\end{array}$ & $\begin{array}{l}\text { Total Famílias } \\
\text { Beneficiadas Programa } \\
\text { Bolsa Família** }\end{array}$ & $\begin{array}{c}\text { \% Famílias beneficiadas } \\
\text { PBF com relação ao } \\
\text { total famílias inscritas } \\
\text { CadÚnico }\end{array}$ \\
\hline Arroio do Tigre & 1.702 & 744 & $43,71 \%$ \\
\hline Boqueirão do Leão & 946 & 383 & $40,48 \%$ \\
\hline Candelária & 4.019 & 1.492 & $37,12 \%$ \\
\hline Encruzilhada do Sul & 4.457 & 2.002 & $44,91 \%$ \\
\hline Estrela Velha & 595 & 200 & $33,61 \%$ \\
\hline General Câmara & 1.263 & 419 & $33,17 \%$ \\
\hline Herveiras & 282 & 136 & $48,22 \%$ \\
\hline Ibarama & 666 & 281 & $42,19 \%$ \\
\hline Lagoa Bonita do Sul & 530 & 175 & $33,01 \%$ \\
\hline Mato Leitão & 335 & 36 & $10,74 \%$ \\
\hline Pantano Grande & 1.265 & 628 & $49,64 \%$ \\
\hline Passa Sete & 824 & 352 & $42,71 \%$ \\
\hline Passo do Sobrado & 597 & 199 & $33,33 \%$ \\
\hline Rio Pardo & 5.417 & 3.110 & $57,41 \%$ \\
\hline Santa Cruz do Sul & 10.294 & 3.514 & $34,13 \%$ \\
\hline Segredo & 1.312 & 578 & $44,05 \%$ \\
\hline Sinimbu & 1.004 & 467 & $46,51 \%$ \\
\hline Sobradinho & 2.438 & 771 & $31,62 \%$ \\
\hline Tunas & 893 & 424 & $47,48 \%$ \\
\hline Vale do Sol & 1.338 & 507 & $37,89 \%$ \\
\hline Vale Verde & 388 & 164 & $42,26 \%$ \\
\hline Venâncio Aires & 7.629 & 2.759 & $36,19 \%$ \\
\hline Vera Cruz & 2.619 & 1.139 & $43,48 \%$ \\
\hline COREDE VRP & 50.813 & 20.480 & $40,30 \%$ \\
\hline RIO GRANDE DO SUL & 1.103 .879 & 414.957 & $37,59 \%$ \\
\hline BRASIL & 27.037 .471 & 13.732.792 & $50,79 \%$ \\
\hline
\end{tabular}

Notas: *Números referentes ao mês de março de 2015.

**Números referentes ao mês de abril de 2015.

Fonte: Caixa Econômica Federal (2015). 
A análise sobre a idade dos beneficiários evidencia uma presença maior de pessoas em algumas faixas etárias específicas, tais como: 10 a 39 anos (30\%); 15 a 49 anos (32\%) e 4 a 9 anos (17\%), conforme apresenta a Figura 2.

Figura 2 - Pessoas beneficiárias do PBF por idade

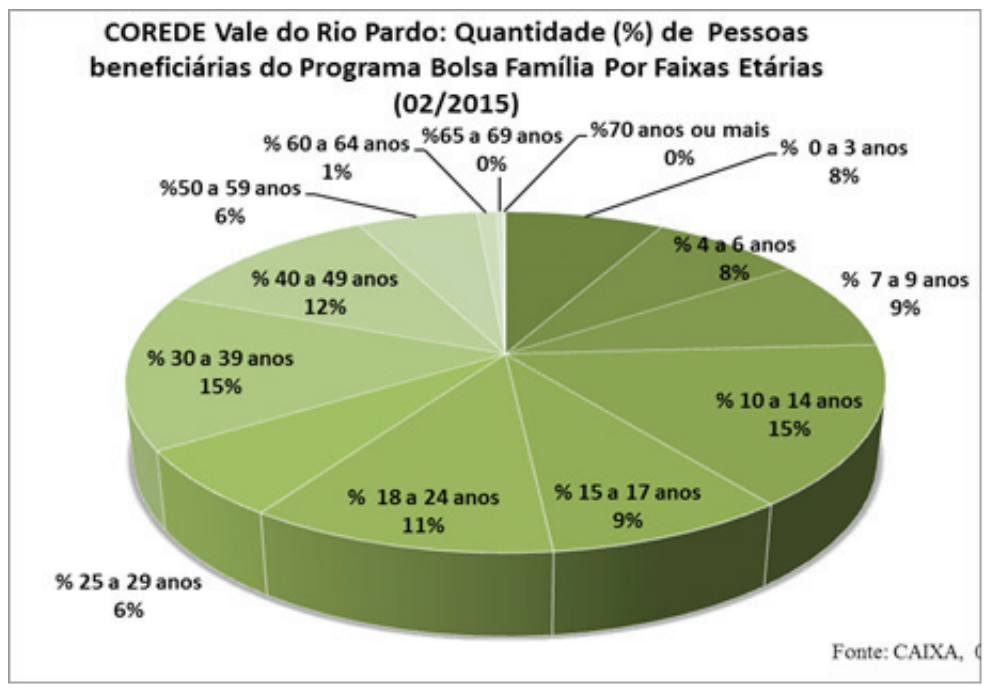

Fonte: Caixa Econômica Federal (2015).

No item seguinte, apresentam-se algumas reflexões sobre a importância do Programa Bolsa Família no enfrentamento à pobreza e sobre sua importância para o desenvolvimento da região a partir da abordagem teórica de Myrdal.

O Programa Bolsa Família e o enfrentamento à pobreza: implicações para o desenvolvimento da região do COREDE do Vale do Rio Pardo

3 Programa do Governo Federal que visa ao enfrentamento da fome e da miséria no país. Foi criado, em 2003, em substituição ao Programa Comunidade Solidária.
Constituído inicialmente no âmbito da Estratégia do Fome Zero ${ }^{3}$, o Bolsa Família representa atualmente o principal programa de enfrentamento à pobreza no Brasil. Integrante do "Plano Brasil Sem Miséria", lançado em junho de 2011 pela Presidente Dilma, o Bolsa Família visa à redução das desigualdades e a promoção da inclusão social. Seu foco de atuação são os milhões de brasileiros que possuem renda 
familiar per capita inferior a $\mathrm{R} \$ 77,00$ mensais, baseando-se na garantia de renda, na inclusão produtiva e no acesso aos serviços públicos (BRASIL, 2015).

A eleição das famílias beneficiárias do Programa Bolsa Família ocorre com base em dois critérios: o atendimento de famílias pobres (renda mensal por pessoa entre $\mathrm{R} \$ 77,01$ e $\mathrm{R} \$ 154,00)$ e o atendimento de famílias extremamente pobres (renda mensal por pessoa de até $\mathrm{R} \$ 77,00)$. A parcela mensal recebida pelos beneficiários é definida com base no perfil da família registrado no Cadastro Único, sendo consideradas algumas informações como a renda mensal por pessoa, o número de integrantes, o total de crianças e adolescentes de até 17 anos e a existência de gestantes.

Os recursos são depositados mensalmente pelo Governo Federal às famílias que fazem parte do programa, que têm acesso ao valor através de saque via cartão magnético, emitido preferencialmente em nome $\mathrm{da}$ mulher. $\mathrm{O}$ valor repassado depende do tamanho da família, da idade dos seus membros e da sua renda, havendo, também, benefícios específicos para famílias com crianças, jovens até 17 anos, gestantes e mães que amamentam.

Analisando-se a média dos valores recebidos no mês de abril de 2015 pelos beneficiários do Programa Bolsa Família que residem nos municípios do COREDE do Vale do Rio Pardo, constata-se que os municípios onde a média de valores é mais alta são: Lagoa Bonita do Sul $(\mathrm{R} \$ 172,62)$; Herveiras $(166,66)$; Arroio do Tigre $(\mathrm{R} \$ 166,23)$ e Pantano Grande ( $\mathrm{R} \$ 160,56)$, respectivamente. Já os municípios que apresentam a média mais baixa, em ordem crescente, são: Mato Leitão ( $\mathrm{R} \$ 124,64)$, Sobradinho ( $\mathrm{R} \$ 131,97)$, Rio Pardo $(\mathrm{R} \$ 132,27)$ e Passo do Sobrado ( $\mathrm{R} \$ 132,72)$, conforme pode ser identificado na Figura 3. 
Figura 3 - Benefício Médio Mensal por família (R\$)

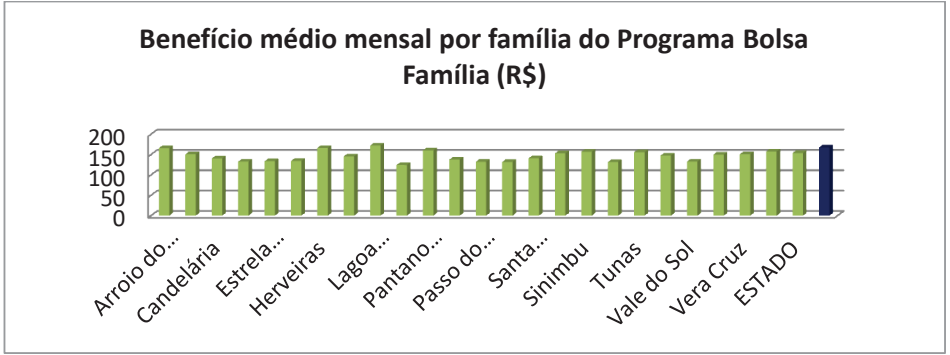

Fonte: Caixa Econômica Federal (2015).

Uma análise mais detalhada sobre os grupos populacionais e específicos evidencia que, nos municípios do COREDE do Vale do Rio Pardo, a maior concentração de beneficiários está entre os agricultores familiares, com 2.122 beneficiários (87\%), seguido dos assentados com 110 beneficiários (5\%). Em terceiro lugar estão os grupos classificados como outros, que correspondem às famílias ciganas, às extrativistas, às pertencentes à comunidade de terreiro, às ribeirinhas, às beneficiárias do Programa Nacional de Crédito Fundiário, às acampadas, às atingidas por empreendimento de infraestrutura e às famílias de presos do sistema carcerário, que totalizam 58 beneficiários (2\%); em quarto lugar, encontram-se os catadores de material reciclável com um total de 55 beneficiários (2\%), conforme apresenta a Figura 4.

No que se refere às famílias de agricultores familiares, constata-se que existe uma concentração delas nos seguintes municípios: Candelária possui um total de 607; Rio Pardo, 495; Segredo, 356; e Encruzilhada do Sul, 204 agricultores familiares beneficiários do $\mathrm{PBF}$, conforme pode ser identificado na Figura 5. 
Figura 4 - Famílias de Grupos Populacionais e específicos beneficiárias do PBF

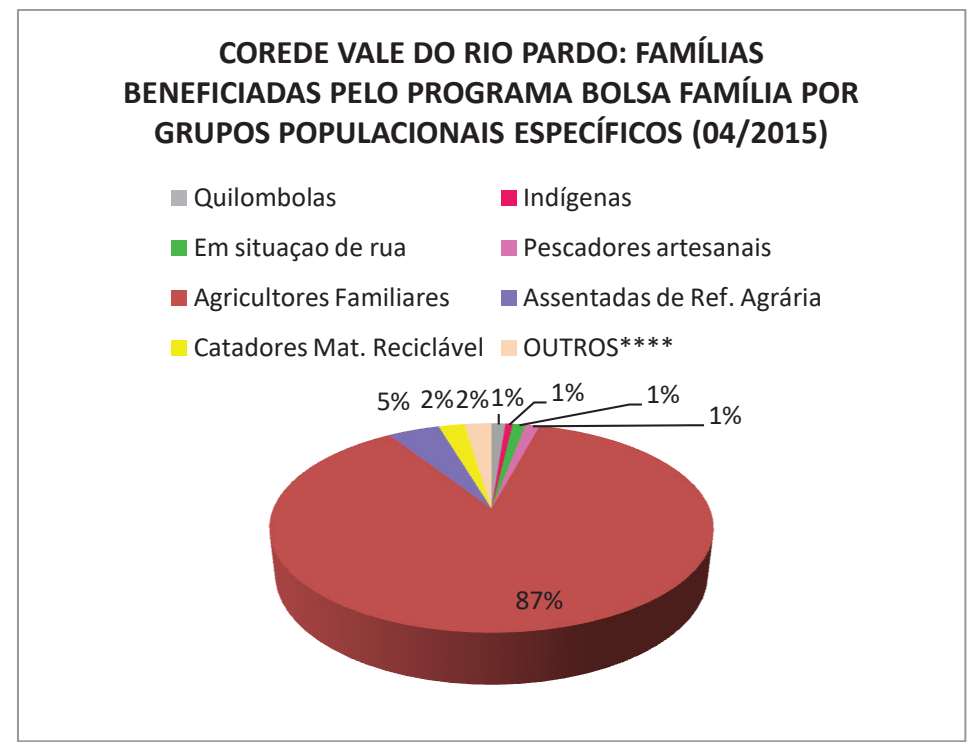

Fonte: Caixa Econômica Federal (2015).

Figura 5 - Famílias de Agricultores Familiares beneficiárias do PBF

\section{FAMÍLIAS DE AGRICULTORES FAMILIARES BENEFICIADAS PELO PROGRAMA BOLSA FAMILIA (04/2015)}

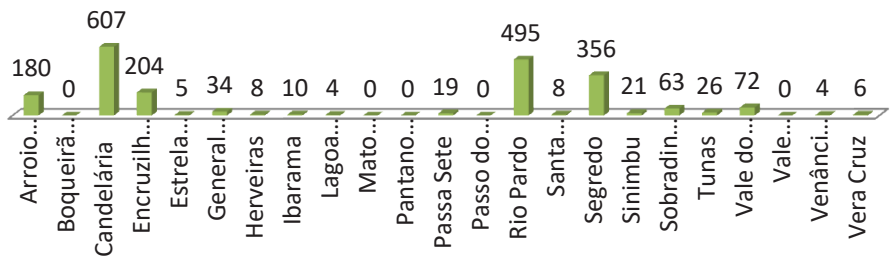

Fonte: Caixa Econômica Federal (2015).

O Programa Bolsa Família prevê o repasse de transferência de renda para famílias que se encontram em situação de vulnerabilidade social em decorrência de diversos fatores que lhes impossibilitam a garantia dos meios necessários para sua manutenção. Nessa perspectiva, o Bolsa Família é um benefício assistencial que integra a Proteção 
social destas famílias, a partir do tripé da Seguridade Social composto pela Assistência Social (para quem dela necessitar), pela Previdência Social (dependente de contribuição) e pela Saúde (de caráter universal) (BRASIL, 1988).

Barros, Carvalho e Mendonça (2010, p. 187) ressaltam que a vulnerabilidade de uma família está diretamente relacionada com "[...] o volume adicional de recursos que ela requer para satisfazer suas necessidades básicas, em relação ao que seria requerido por uma família padrão". Nesse sentido, considerando-se que um dos critérios de eleição dos beneficiários do Programa Bolsa Família é a existência de renda mensal entre $\mathrm{R} \$ 77,01$ e $\mathrm{R} \$ 154,00$ por pessoa, sendo, portanto, classificados como "pobres"; e renda de até $\mathrm{R} \$ 77,00$ por pessoa, o que os classifica como "extremamente pobres"; assim, pode-se considerar que todos estes sujeitos estão em situação de vulnerabilidade social.

Nesse sentido, de acordo com Myrdal, essa situação de vulnerabilidade que pode ser representada pelo círculo vicioso da pobreza somente seria interrompida pela ação do Estado a partir de intervenções políticas planejadas visando à redução dos níveis de pobreza. Entre os anos de 2003 e 2011, a renda per capita brasileira aumentou mais de 40,0\%, de cerca de $\mathrm{R} \$ 550,00$ para pouco mais de $\mathrm{R} \$ 770,00$; e a desigualdade medida pelo coeficiente de Gini caiu 9,2\%, de 0,576 para 0,523. A extrema pobreza no Brasil teve queda de $8 \%$ para pouco mais de $3 \%$ da população, e a pobreza recuou de $16 \%$ para $6 \%$. Por trás destes dados, devemos salientar, há dois fenômenos além do Bolsa Família, sendo: os reajustes do salário mínimo que tornou-se um alívio para a pobreza, aliado à expansão do mercado de trabalho, contribuiu para tirar da pobreza e da extrema pobreza um grande número de famílias brasileiras (SOUZA; OZORIO, 2014).

No período de 2009-2010 foi criado o Sistema de Gestão do Programa Bolsa Família (SigPBF), o qual passou a integrar os demais sistemas operacionais da SENARC/ 
MDS, bem como foram alteradas algumas questões relativas ao acompanhamento das condicionalidades. No ano de 2009, foi aprovado, pela Comissão de Intergestores Tripartite da Assistência Social, o "Protocolo de Gestão Integrada de Benefícios e Serviços" no âmbito do SUAS, no qual foram definidos procedimentos para o acompanhamento em âmbito familiar de beneficiários do PBF, do BPC e do Peti, que deverão ser realizados a partir dos Centros de Referência da Assistência Social (CRAS e CREAS).

Com isso, identifica-se que:

A estratégia de acompanhamento familiar é um marco para o $\mathrm{PBF}$, pois ele assinala vários movimentos importantes: a integração entre benefícios e serviços na prestação da assistência social, a aproximação entre as esferas da assistência, saúde e educação, e a consolidação do enfoque não punitivo das condicionalidades no programa. (COTTA; PAIVA, 2010, p. 61).

A partir do Protocolo de Gestão Integrada de Benefícios e Serviços (BRASIL, 2009) está previsto que o atendimento das famílias beneficiárias do PBF poderá ser diferenciado dependendo da situação de vulnerabilidade e de risco social, da qual serão priorizadas: as famílias que vivenciam situações de risco social; famílias em situação de descumprimento de condicionalidades, em especial, aquelas que estão em "suspensão do benefício por dois meses", a fim de garantir sua segurança de renda.

Segundo a Portaria GM/MDS n³ 321, de 29 de setembro de 2008, está explicito que, a partir das condicionalidades, o $\mathrm{PBF}$ pode contribuir para reforçar o acesso das famílias às políticas de saúde, de educação e de assistência social e, assim, promover a melhoria das condições de vida dessas famílias que se encontram em situação de vulnerabilidade. Os efeitos aplicados às famílias são gradativos de acordo com o histórico de descumprimento de cada uma delas. Para as famílias com 
crianças e adolescentes até 15 anos, nutrizes ou gestantes, que não cumprirem as condicionalidades, ficam sujeitas aos seguintes efeitos, aplicados de forma sucessiva:

I - advertência, no primeiro registro de descumprimento; II - bloqueio do benefício por um mês, no segundo registro de descumprimento; III - suspensão do benefício por dois meses, no terceiro registro de descumprimento; IV - suspensão do benefício por dois meses, no quarto registro de descumprimento; e V - cancelamento do benefício, no quinto registro de descumprimento. (BRASIL, 2009).

Para as famílias beneficiárias com adolescentes na faixa etária entre 16 e 17 anos, que sejam beneficiários do Benefício Variável Jovem, e que não cumprirem as condicionalidades, ficam sujeitas aos seguintes efeitos, aplicados de forma sucessiva: “ I - advertência, no primeiro registro de descumprimento do adolescente; II - suspensão do BVJ por dois meses, no segundo registro de descumprimento o Adolescente; e III - cancelamento do BVJ, no terceiro registro de descumprimento do adolescente" (BRASIL, 2008).

Está previsto, ainda, que as famílias que estejam inseridas nos serviços socioassistenciais do SUAS deverão ter o seu Cadastro Único realizado ou atualizado, caso já estejam inscritas nesse banco de dados. Considera-se como acompanhamento familiar o

[...] desenvolvimento de intervenções desenvolvidas em serviços continuados, com objetivos estabelecidos, que possibilite à família o acesso a um espaço onde possa refletir sobre sua realidade, construir novos projetos de vida e transformar suas relações - sejam elas familiares ou comunitárias. (BRASIL, 2009, p. 20).

Está previsto, ainda, que as famílias que estejam inseridas nos serviços socioassistenciais do SUAS deverão ter o seu Cadastro Único realizado ou atualizado, caso já 
estejam inscritas nesse banco de dados. Considera-se como acompanhamento familiar o

[...] desenvolvimento de intervenções desenvolvidas em serviços continuados, com objetivos estabelecidos, que possibilitem à família o acesso a um espaço onde possa refletir sobre sua realidade, construir novos projetos de vida e transformar suas relações - sejam elas familiares ou comunitárias. (BRASIL, 2009, p.20).

Conforme referido por Sen (2000), pensar no desenvolvimento de uma determinada região implica o reconhecimento das condições objetivas de vida da população, e, especialmente, requer a compreensão sobre as "liberdades individuais” dos sujeitos. Estas, por sua vez, pressupõem a eliminação de todas as fontes limitadoras, especialmente a pobreza, a carência de oportunidades econômicas, as distintas formas de privação social, entre outros aspectos. Nesse sentido, os sujeitos somente terão garantidas suas liberdades individuais na medida em que tiverem acesso aos direitos básicos como alimentação, saúde, educação, oportunidades de lazer, de se expressarem livremente, entre outros.

Na mesma perspectiva, Pires et al. (2011, p. 63) referem que o desenvolvimento regional pode ser considerado como

[...] um processo institucional que objetiva corrigir os grandes desníveis regionais de renda, emprego e capital (infraestrutura, industrial etc.), estimulando as regiões a obterem certo dinamismo socioprodutivo e organizacional que lhes capacitem no caminho da autonomia e do crescimento sustentado.

Para Myrdal, o círculo vicioso do atraso econômico e da pobreza poderia ser interrompido por meio das intervenções do Estado que promoveriam o desenvolvimento regional. A questão regional passou a ganhar ênfase no Brasil especialmente a partir dos anos de 1990, por meio de iniciativas como a criação do Ministério da Integração Nacional em 1999, o que possibilitou um processo de reorganização do 
Estado e a busca de formulação e condução de políticas, planos e programas de desenvolvimento que contemplassem estratégias de incorporação de regiões periféricas, como as discussões sobre a Política Nacional de Ordenamento Territorial (PNOT) e a criação da Política Nacional de Desenvolvimento Regional (PNDR) (CARGNIM, 2014), entre outros.

No caso do Estado do Rio Grande do Sul, Brasil, onde se localizam os municípios do COREDE do Vale do Rio Pardo, espaço geográfico delimitado para este estudo que ora se apresenta, no que tange ao desenvolvimento regional merece destaque a criação dos Conselhos Regionais de Desenvolvimento (COREDEs). A partir de um contexto resultante da Constituição Federal de 1998 e da Constituição Estadual de 1989, os COREDES foram constituídos em 1991 através da aproximação do governo com a sociedade civil e com instituições regionais, especialmente as universidades. Constituem-se como espaço plural e aberto de construção de parcerias sociais e econômicas, em nível regional, através da articulação política dos interesses locais e setoriais em torno de estratégias próprias e específicas de desenvolvimento para as regiões. O estado do Rio Grande do Sul, Brasil, possui atualmente 28 COREDEs que, a partir de suas particularidades e limites, se constituem como importantes instâncias de planejamento governamental que reúnem diversos representantes da sociedade civil, organizando a participação dos distintos sujeitos e promovendo debates sobre o desenvolvimento das regiões (COREDES, 2010).

Merecem destaque, ainda, as iniciativas desenvolvidas a partir do Fórum dos COREDEs, especialmente a elaboração do Documento denominado "Pró-RS V", da qual foram definidas propostas estratégicas para o desenvolvimento regional do Estado do Rio Grande do Sul para o período de 2015-2018. No caso específico do COREDE do Vale do Vale do Rio Pardo, o referido documento enfatiza o 
fortalecimento da agricultura familiar e a implantação e/ou organização de agroindústrias (COREDES, 2014), iniciativas importantes para o desenvolvimento da região, considerandose que a maioria dos beneficiários do Programa Bolsa Família pertencentes a grupos específicos são agricultores familiares, conforme já referido.

Dessa forma, observa-se que o Bolsa Família pode contribuir para corromper o círculo vicioso da pobreza que Myrdal (1997) retrata em sua teoria. O Programa é a primeiro programa de governo que tem como objetivo principal enfrentar a pobreza garantindo a todas as famílias pobres, além de uma renda complementar, o acesso a direitos sociais. O Programa apresentou uma trajetória de sucesso, contribuindo efetivamente na melhoria da qualidade de vida de milhões de brasileiros (CAMPELLO, 2013).

Hoffmann (2013, p. 215) analisa a redução da desigualdade da distribuição da renda no Brasil e salienta que, a partir de 1995, “[...] todas as análises constatam a grande importância das mudanças na distribuição do rendimento do trabalho, mas todas mostram também a extraordinária contribuição das transferências sociais, particularmente do Bolsa Família, dada sua pequena participação da renda total”. Entre os anos de 2001 e 2011, as transferências por meio do Bolsa Família e o Benefício de Prestação Continuada (BPC) colaboraram de 15\% a $20 \%$ da redução da desigualdade de renda.

A transferência por meio do cartão magnético, preferencialmente em nome da mulher - visto que $93 \%$ dos titulares são mulheres -, proporciona não somente um empoderamento feminino mas também uma possível saída da dominação do gênero masculino, conforme demostra o trabalho de Rêgo e Pinzani (2013). O Programa apresentou resultados relevantes quanto à diminuição da desnutrição, da insegurança alimentar e nutricional e da mortalidade infantil, tanto a mortalidade relacionada à resistência a doenças 
infectocontagiosas quanto à relacionada com a desnutrição e a diarreia (RASELLA et al., 2013).

Os resultados na educação, conforme demostram Craveiro e Ximenes (2013), evidenciam que os alunos beneficiários do Bolsa Família tiveram melhor desempenho do que os demais alunos da rede pública, e a evasão escolar foi menor entre os beneficiários do que entre os não assistidos pelo Programa.

O Bolsa Família, devido à sua cobertura e focalização, vem se consolidando como uma experiência bem-sucedida. O Programa apresenta muitos pontos positivos, pois os objetivos foram alcançados e identificam-se avanços em outros aspectos não previstos, como o empoderamento feminino, o que se pode destacar como uma história de sucesso no combate à pobreza. Evidenciou-se, ainda, que os dados analisados indicam que há uma possibilidade de erradicação da extrema pobreza no país e a quebra do seu círculo vicioso, caso os resultados do Programa apresentem o mesmo desempenho identificado na última década.

\section{Considerações finais}

O Brasil tem evoluído no processo de criação de políticas sociais públicas que resultaram na melhoria de alguns indicadores de pobreza, especialmente relacionados com as áreas da saúde e da educação. O Bolsa Família, criado em 2003, tem promovido mudanças na vida de milhões de pessoas, principalmente daquelas que não tinham acesso à alimentação e que se encontravam em condição de extrema pobreza, passando a ser atendidas por uma rede de proteção social.

A pobreza, portanto, envolve dimensões sociopolíticas e institucionais, sendo dever do Estado enfrentá-la por intermédio de políticas direcionadas à redução das desigualdades e à inclusão dos indivíduos que se encontrem 
em situação de risco social. Percebe-se que o Bolsa Família está contribuindo para mudar significativamente os níveis de concentração de renda e de pobreza no país e tem produzido impactos positivos no aumento do bem-estar das pessoas assistidas, especialmente em decorrência de melhorias na alimentação devido ao aumento da aquisição de bens e de serviços.

Evidenciou-se, ainda, que os dados analisados indicam que há uma possibilidade de erradicação da extrema pobreza no país e a quebra do seu círculo vicioso, conforme identificado por Myrdal em sua abordagem teórica, caso os resultados do Programa apresentem o mesmo desempenho identificado na última década.

Por fim, embora sejam reconhecidos os inúmeros benefícios deste programa para a população mais empobrecida do país, há que se considerar, também, que o Brasil é um dos países com maiores índices de desigualdades sociais do mundo, o que requer a articulação do Programa Bolsa Família com outras políticas públicas tendo em vista a garantia da inclusão social, a mudança da condição de extrema pobreza e a redução das desigualdades sociais.

O Programa Bolsa Família vem se firmando como uma experiência bem-sucedida, em virtude de sua ampla cobertura e focalização, o que demonstra relevantes impactos sobre as condições de vida da população assistida e no rompimento do círculo vicioso da pobreza.

\section{Referências}

BARROS, Ricardo Paes; CARVALHO, Mirela; MENDONÇA, Rosane Silva Pinto. Sobre as utilidades do Cadastro Único. In: CASTRO, Jorge Abrahão; MODESTO, Lucia (Org.). Bolsa Família 2003-2010: avanços e desafios. Brasília: IPEA, 2010. p. $179-212$.

BRASIL. Constituição (1988). Constituição da República do Brasil. Brasília, DF: Senado, 1988. 
- Ministério do Desenvolvimento Social e Combate à Fome. Comissão Intergestores Tripartite. Resolução CIT No 7, de 10 de Setembro de 2009. Protocolo de Gestão Integrada de Serviços, Benefícios e Transferências de Renda no âmbito do Sistema Único de Assistência Social (SUAS). Brasília, 2009.

. Programa Bolsa Família. Disponível em: <http:// www.mds.gov.br>. Acesso em: 26 maio 2015.

CAIXA ECONÔMICA FEDERAL. Folha de Pagamentos do PBF. 2015.

CAMARGO, José Márcio. Políticas sociais no Brasil: prioridades erradas, incentivos perversos. São Paulo em Perspectiva, v. 18, n. 2, p. 68-77, abr./jun. 2004.

CAMPELLO, Tereza. Uma década derrubando mitos e superando expectativas. In: CAMPELLO, Tereza; NERI, Marcelo Côrtes. Programa Bolsa Família uma década de inclusão e cidadania. Brasília: IPEA, 2013. p. 15-24.

CARDOSO, Fernanda Graziela. A armadilha do subdesenvolvimento: uma discussão no período desenvolvimentista brasileiro sobre a ótica da abordagem da complexidade. 2012. 263 f. Tese (Doutorado em Economia) - Programa de Pós-Graduação em Economia, Universidade de São Paulo, São Paulo, 2012.

CARGNIM, Antônio Paulo. Políticas de Desenvolvimento Regional no Rio Grande do Sul: Vestígios, Marcas e Repercussões Territoriais. Brasília: Ministério da Integração Nacional, 2014.

\section{CONSELHOS REGIONAIS DE DESENVOLVIMENTO (COREDEs)}

CRAVEIRO, Clélia Brandão Alvarenga; XIMENES, Daniel de Aquino. Dez anos do Programa Bolsa Família: desafios e perspectivas para a universalização da educação básica no Brasil. In: CAMPELLO, Tereza; NERI, Marcelo Côrtes. Programa Bolsa Família uma década de inclusão e cidadania. Brasília: IPEA, 2013. p. 109-124.

COTTA, Tereza Cristina; PAIVA, Luis Henrique. O Programa Bolsa Família e a proteção social no Brasil. In: CASTRO, Jorge Abrahão; MODESTO, Lucia (Org.). Bolsa Família 2003-2010: avanços e desafios. Brasília: IPEA, 2010. p. 57-100. 
HOFFMANN, Rodolfo. Transferências de renda e desigualdade no Brasil (1995-2011). In: CAMPELLO, Tereza; NERI, Marcelo Côrtes. Programa Bolsa Família uma década de inclusão e cidadania. Brasília: IPEA, 2013. p. 207-216.

INSTITUTO BRASILEIRO DE GEOGRAFIA E ESTATÍSTICA. Disponível em: <http://www.ibge.gov.br/home/>. Acesso em: 21maio. 2015.

INSTITUTO DE PESQUISA ECONÔMICA APLICADA. Disponível em: <http://www.ipeadata.gov.br/>. Acesso em: 15 maio 2015.

JANNUZZI, Paulo de Martino; PINTO, Alexandro Rodrigues. Bolsa Família e seus impactos nas condições de vida da população brasileira: uma síntese dos principais achados da pesquisa de avaliação de impacto do Bolsa Família II. In: CAMPELLO, Tereza; NERI, Marcelo Côrtes. Programa Bolsa Família uma década de inclusão e cidadania. Brasília: IPEA, 2013. p. 179-192.

LIMA, Ana Carolina da Cruz; SIMÕES, Rodrigo Ferreira. Texto para Discussão no 358. Teorias do desenvolvimento regional e suas implicações de política econômica no Pós-Guerra: o caso do Brasil. Belo Horizonte: UFMG/Cedeplar, 2009.

MYRDAL, Gunnar. Aspectos políticos da teoria econômica. 2. ed. São Paulo: Nova Cultural, 1997.

NURKSE, Ragnar. [1953]. Problema da formação de capital em países subdesenvolvidos. Rio de Janeiro: Editora Civilização brasileira, 1957.

RÊGO, Walquíria Domingues Leão; PINZANI. Alessandro. Liberdade, dinheiro e autonomia: o caso do Programa Bolsa Família. In: CAMPELLO, Tereza; NERI, Marcelo Côrtes. Programa Bolsa Família uma década de inclusão e cidadania. Brasília: IPEA, 2013. p. 359-366.

SANSON, Milton. O Estado e as políticas públicas no combate à desigualdade social: o PBF (Mestrado em Direito Político e Econômico) - Universidade Presbiteriana Mackenzie, São Paulo, 2007.

RASELLA, Davide; AQUINO, Rosana; SANTOS, Aquino Carlos A. T.; PAES-SOUZA, Rômulo; BARRETO, Mauricio L. Efeitos do Programa Bolsa Família sobre a mortalidade em crianças: uma 
análise nos municípios brasileiros. In: CAMPELLO, Tereza; NERI, Marcelo Côrtes. Programa Bolsa Família uma década de inclusão e cidadania. Brasília: IPEA, 2013. p. 247-262.

SEN, Amartya. Desenvolvimento como liberdade. São Paulo: Companhia das Letras, 2000.

SILVA, Maria Ozanira da Silva. Os programas de transferência de renda e a pobreza no Brasil: superação ou regulação. Revista de Políticas Públicas, São Luís, v. 9, n. 1, p. 1-27, 2005.

O Bolsa Família: problematizando questões centrais na política de transferência de renda no Brasil. Revista Ciência e Saúde Coletiva, Rio de Janeiro, v. 12, n. 6, p. 1429-1439, 2007.

SOUZA, Pedro Herculano Guimarães Ferreira de; OZORIO, Rafael Guerreiro. O perfil da pobreza no Brasil e suas mudanças entre 2003 e 2010. In: CAMPELLO, Tereza; NERI, Marcelo Côrtes. Programa Bolsa Família uma década de inclusão e cidadania. Brasília: IPEA, 2013. p. 139-156

SOARES, Serguei; SÁTYRO, Natália. O Programa Bolsa Família: desenvolvimento institucional e possibilidades futuras. In: CASTRO, Jorge Abrahão; MODESTO, Lucia (Org.). Bolsa Família 2003-2010: avanços e desafios. Brasília: IPEA, 2010. p. 2556.

PIRES, Elson L. S.; FUINI, Lucas Labigalini; MANCINI, Rodrigo Furgieri; PICCOLI NETO, Danilo. Governança Territorial. Conceito, Fatos e Modalidades. Rio Claro: UNESP-IGCE/ Programa de Pós-Graduação em Geografia, 2011.

Submetido em: 08/09/2016

Aceito em: 29/06/2017 


\title{
THE VICIOUS CIRCLE OF POVERTY: ANALYSIS OF THE STRATEGY OFTHE BOLSA FAMÍLIA PROGRAM INTHE MUNICIPALITIES OFTHE COREDE OFTHE RIO PARDO VALLEY
}

\begin{abstract}
The Brazil, despite being one of the largest economies in the world, still presents great socioeconomic inequalities. As a strategy to combat hunger and poverty, the Bolsa Família Program was created in 2003, which in 12 years has managed to remove more than 36 million people from poverty and poverty. The main objective of this article is to analyze if the Bolsa Família contributed to reduce the vicious circle of poverty highlighted by economist Gunnar Myrdal (1997) in his theoretical approach to development. With regard to the methodological issues of this article, a documentary research on Myrdal's development theory (1997) was carried out, along with a descriptive analysis based on secondary data of the Bolsa Família Program at the regional level in Conselho Regional de Desenvolvimento (COREDE) Vale do Rio Pardo. It was verified that the Bolsa Família can contribute to corrupt the vicious circle of poverty that Myrdal (1997) portrays in his theory, because, it contributes to the reduction of hunger and malnutrition, since, great part of the benefits is used for the care The basic needs of families, especially food. It was also evidenced that the data analyzed indicate that there is a possibility of Bolsa Família contributing to the process of eradicating extreme poverty in the country and breaking its vicious circle if the results of the Program show the same performance identified in the last decade. Finally, while recognizing the numerous benefits of this program for the country's most impoverished population, we must also consider the need to articulate the Bolsa Família Program with other public policies.
\end{abstract}

Keywords: Vicious Circle. Poverty. Bolsa Família Program. 